\title{
is Research Square \\ Hepatocellular carcinoma with right atrial tumor thrombus: a systematic review
}

\section{Shi-Min Yuan}

The First Hospital of Putian, Teaching Hospital, Fujian Medical University https://orcid.org/0000-00021773-2959

Yi-Xian Guo ( $\square$ ptgyx163@163.com )

https://orcid.org/0000-0001-6883-291X

\section{Research article}

Keywords: Hepatocellular carcinoma; right atrium; tumor thrombi; thalidomide.

Posted Date: February 24th, 2020

DOI: https://doi.org/10.21203/rs.2.22554/v2

License: (1) This work is licensed under a Creative Commons Attribution 4.0 International License. Read Full License 


\section{Abstract}

Background: Hepatocellular carcinoma with right atrial tumor thrombus is uncommon but with a dismal prognosis. Methods: By comprehensive literature retrieval of 2000-2019, 53 reports were obtained with 187 patients recruited into this study. The extracted data included patient characteristics, tumor characteristics, treatment, follow-up and outcomes. Statistical analyses applied were student t, Fisher exact and 12 tests. Patients were divided into 6 groups according to the treatment of choices: transarterial chemoembolization (TACE), surgery, radiotherapy, chemotherapy, intervention and supportive care. Results: The overall survival rate of this cohort was $40.8 \%$. The survival rate of patients receiving TACE was $33.3 \%$ and that of surgical patients was $41.9 \%$. The survival time of patients with TACE treatment was longer than surgical patients, but lack of statistical significance. Patients were under a follow-up of $15.7 \pm 16.6$ (median 10) months. Patients receiving radiotherapy had under a longest follow-up among all groups. Intra- and/or extrahepatic recurrence of hepatocellular carcinoma was the major morbidity and also often causes of death. The mortality rates of patients with different treatments in a decremental sequence were supportive care >radiotherapy >surgery >TACE >intervention. No difference was noted in mortality between patients reported from case reports and those from non-case reports. Conclusions: Even though advanced hepatocellular carcinoma with right atrial thrombus is an aggressive malignancy, the present study showed that patients' prognoses were improved and survival time elongated with active treatments such as TACE and surgery. Active treatments were thus advised to patients with hepatocellular carcinoma with right atrial tumor thrombus.

\section{Background}

Hepatocellular carcinoma (HCC) is an aggressive malignancy with a potential to invade intrahepatic vasculatures [1]. HCC with a tumor thrombus extending into the right atrium (RA) via the inferior vena cava (IVC) is rare, with a documented incidence of $1-4.8 \%$ in autopsy series [1, 2], but it is increasingly reported clinically with the development of medical imaging techniques [3]. The advanced HCC can be managed by non-surgical treatments, such as conservative treatment, transarterial chemoembolization (TACE) and radiotherapy [4]. Nevertheless, HCC patients with RA tumor thrombus often have a dismal prognosis and limited survival time, and respond poorly to the usual therapeutics [4]. Moreover, RA tumor thrombi often lead to sudden death as a result of right heart failure, tricuspid orifice occlusion, or pulmonary embolism [4]. Therefore, aggressive surgical treatment of HCC with RA tumor thrombus has been attempted. However, there is not any consensus on the therapeutic regimens of advanced HCC [3]. This article is intended to give an overview of advanced HCC with RA tumor thrombus and to discuss the management and outcomes.

\section{Methods}

English language literature was carefully retrieved in the PubMed database for articles published 20002019. The keywords entered in this search to identify articles were "hepatocellular carcinoma", "liver tumor", "tumor thrombus" and "right atrium". The screening of the bibliographic references helped in 
completing the literature retrieval. The inclusion criteria were clinical research, case series, or case report of HCC with RA thrombus with substantial patient information for statistical analysis. Seventy articles were found related to the topic and keywords in the literature search. The exclusion criteria were articles reporting: $\mathrm{HCC}$ with right ventricle metastasis $(n=6), \mathrm{HCC}$ with portal vein or IVC thrombus without RA extension ( $n=3)$, RA invasion by metastatic esophageal/pancreas/colon carcinoma $(n=3)$, HCC with RA thrombus where patient information was scanty $(n=2)$, fibrolamellar hepatocellular carcinoma with RA thrombus $(n=1)$, liver transplantation in Budd-Chiari syndrome $(n=1)$ and cardiac complications after liver transplantation $(n=1)$. In total, 17 articles were excluded and 53 articles were considered materials of the present review.

The data independently extracted from each study were patient characteristics, tumor characteristics, treatment, follow-up and outcomes. Data extraction was proceeded by tabulating all the necessary information of each report. This process was repeated three times to avoid omissions and ensure the integrity and credibility of the data. Publication bias that might come from the case reports and case series might affect the cumulative evidence.

The quantitative data were expressed in mean \pm standard deviation and were compared by independent samples $t$-test. Categorical variables were compared with Fisher exact test with continuity correction. $p<0.05$ was considered statistically significant. The extent of heterogeneity was determined by an $R$ method, and a $p$ value of $<0.1$ was taken at a statistically significant level of heterogeneity.

\section{Results}

\section{Patient Characteristics}

In total 53 articles were collected [1-53], including 5 (9.4\%) retrospective studies [3, 11, 23, 50, 53 ], 4 (7.5\%) case series [1, 21, 43, 49], and $44(83.0 \%)$ case reports [2, 4-10, 12-20, 22, 24-42, 44-48, 51, 52], with 187 patients involved. Even though cohort studies, case-control studies and case series are considered to form a hierarchy of increasing risk of bias. These studies reflected closely a routine practice or the usual setting where the intervention would be implemented. The heterogeneity between the studies was not significant.

On current admission, patients were at the age of $58.7 \pm 12.4$ (range, 23-84; median, 60$)$ years $(n=93)$. Gender was known for 105 patients: 88 (83.8\%) were male and $17(16.2 \%)$ were female $\left(\chi^{2}=96.0\right.$, $p<0.001)$. In total $166(88.8 \%)$ patients had a medical history of liver disease (Table II).

Patients were divided into 6 groups according to the treatment of choices: TACE, surgery, radiotherapy, chemotherapy, intervention and supportive care. Besides, some patients were not treated, while treatment was not described in others.

In 8 patients with recurrent $\mathrm{HCC}$, treatment had been done with hepatectomy in $2(25 \%)$ patients $[1,30]$, TACE in $3(37.5 \%)$ patients [1, 19], and TACE plus direct-acting antiviral therapy (sofosbuvir) [5], 
radiofrequency ablation plus doxorubicin and sorafenib chemotherapy [15], and TACE plus radiofrequency ablation plus sorafenib [40] in 1 (12.5\%) patient each.

The clinical symptoms were described for 36 patients, with pedal edema being the most common (Table I). Laboratory investigational results on admission were shown in Table III.

The timing of diagnosis of RA thrombi was described for 53 patients. The diagnosis was made at the time of HCC recurrence in $5(9.4 \%)$ patients $[1,5,13,15,30]$, in the progression of HCC in $13(24.5 \%)$ patients $[1,17,19,34,36-38,40,42,48,51]$, and simultaneously with primary HCC in $35(66.0 \%)$ patients $[2,4,6-10,12,14,16,18,20-22,24-29,31-33,35,39,41,44-47,49,52]$.

The time interval between diagnoses of HCC and of RA tumor thrombus was $33.5 \pm 22.1$ (range, 9-56; median, 35) months $(n=4)$ for patients with recurrent HCC and 33.4 \pm 46.2 (range, 2-144; median, 12) months $(n=9)$ for patients at HCC progression $(t=0.002, p=0.998)$.

\section{Tumor Characteristics}

The size of the liver tumor was described for 57 patients. The calculated tumor size was $8.4 \pm 4.1$ (range, $1.3-21$; median, 7.6$) \mathrm{cm}$, with only $3(5.3 \%)$ tumors of 3 patients $<3 \mathrm{~cm}[1,6,51]$.

The locations of liver tumors were described for 56 patients: 16 (28.6\%) were located in the left lobe [2, 8, $12,16-18,21,27,31,35,46,47,52,53]$, one of which extended to the right lobe at a later stage [17], while 35 (62.5\%) tumors were located in the right lobe $[1,6,7,9,10,13,14,20-22,24,28,29,34,39,41,42,48$, $49,53]$, and $5(8.9 \%)$ involved both lobes $[25,26,32,33,53]\left(\chi^{2}=37.0, p<0.001\right)$. There was no significant difference in tumor size between tumors located in the left and in the right lobes $(8.6 \pm 4.2 \mathrm{~cm}$ vs. $8.9 \pm 4.4$ $\mathrm{cm}, t=-0.207, p=0.837)$.

The segmental locations of liver tumors were described for 31 patients, and a total of 68 segments were invaded with 1-4 invaded segments in each patient $[2,10,13,18,21,22,25,27-29,34,41,42,53]$. Segments 7 and 8 were the most commonly invaded by liver tumors (Figure 1).

Apart from RA thrombus, tumor thrombus in alternative vasculatures developed in 106 (56.7\%) patients, and IVC thrombus was the most frequent (Table IV). Maximal size of RA tumor thrombus was $4.6 \pm 2.3$ (range, 2-15; median, 4.4) $\mathrm{cm}(\mathrm{n}=42)$. RA tumor thrombus-induced tricuspid orifice occlusion of different degrees was noted in 3 patients $[10,15,31]$.

Simultaneous lung metastasis was noted in 6 patients $[2,8,10,17,37,47]$. Diaphragm metastasis occurred in 1 patient [7].

\section{Treatment}

Liver tumor resection was performed with RA tumor thrombi remained followed by chemotherapy with bevacizumab in 1 patient [48], and RA and IVC tumor thrombi removal followed by microwave 
ablation/TACE for liver tumor in 2 patients $[26,16]$. Their survival time was 6,6 and 7 months, respectively (median, 6 months).

The 30 patients with a one-stage operation for both HCC and RA thrombus survived $14.4 \pm 12.8$ (range, 1.3-56; median, 11.2) months $(n=25)[2-4,12,13,18,20,21,25,28-30,35,42,43,45,49-52]$. One patient receiving a two-stage operation survived 6 months [38]. The surgical operation was performed under cardiopulmonary bypass (CPB) in 18 patients $[2,3,18,21,28-30,35,38,43,45,51,52]$, under veno-venous bypass in 1 patient [25] and with total hepatic vascular exclusion (THVE) with no CPB in 15 patients $[3,4,12,13,20,42,49,50]$.

The operation time was $9.1 \pm 2.5$ (range, 5.6-12.3; median 9.0) hours $(n=12)[4,7,12,25,29-31,35,42$, $45,51,52]$, the CPB time was $40.6 \pm 23.9$ (range, 16-100; median, 38) $\min (n=9)[2,7,12,29,30,45,50,51$, 52], and the hepatic occlusion time was $29.4 \pm 26.3$ (range, 10-87; median, 19) $\min (n=11)[4,12,13,20,25$, $29-31,42,45,52]$. The total blood loss amount was 3.562,0 $\pm 2,692.2$ (range, 650-8,200; median, 2,692) $\mathrm{mL}(\mathrm{n}=10)[7,13,25,29-31,35,42,51,52]$.

TACE, solely or combined with chemotherapy/radiotherapy/surgery, was done 1-7 time per patient, and thalidomide $100 \mathrm{mg}$ bid was the usual regimen. Complete/partial regression of liver and RA tumor, afetoprotein decrease and symptom-free were observed at 1-4 months [1]. Selective embolization with pirarubicin $30 \mathrm{mg}$, oxaliplatin $200 \mathrm{mg}$, hydroxycamptothecine $20 \mathrm{mg}$ and iodized-oil was also reported obtaining similar effects to thalidomide [46].

Systemic chemotherapy with sorafenib were applied in 4 patients $[9,14,27,47]$.

Interventional therapy was performed in 2 patients: mechanical thrombectomy of the mobile right atrial mass using the AngioVac cannula thrombectomy catheter with subcutaneous enoxaparin and oral sorafenib in one who did not respond to sorafenib and died [41] and percutaneous microwave ablation in another but intrahepatic tumor recurrence at 3 months while tumors were completely ablated by TACE and salvage microwave ablation who was alive [22].

Radiotherapy included external beam radiotherapy with 2500 cGy in 5 fractions in one patient, the RA mass was reduced at 1 month but died of multiple metastasis [15] and hypofractionated radiotherapy in 18 patients with 2 alive at a follow-up of 3-40 month [23]. The outcomes of each group were shown in Table V.

\section{Follow-up and Survival data}

Patients were under a follow-up of $15.7 \pm 16.6$ (range, $0.5-97$; median 10$)$ months $(n=75)$. Patients receiving radiotherapy had under a longest follow-up among all groups (Table $\mathrm{VI}$ ). Intra- and/or extrahepatic recurrence of HCC was the major morbidity and also the cause of death in most cases (Table VII). 
The overall survival rate of this cohort was $40.8 \%(20 / 49)$. The survival rate of patients receiving TACE was $33.3 \%(4 / 12)$ and that of surgical patients was $41.9 \%(13 / 31)\left(\chi^{2}=0.3, p=0.735\right)$. The prognoses of the patients with different treatments were shown in Table V. The survival time of TACE patients was longer than that of surgical patients, but lack of a statistical significance $(20.0 \pm 3.4$ months vs. $13.3 \pm 12.1$ months, $t=-1.455, p=0.151)$. The mortality rates of patients with different treatments in a decremental sequence were supportive care $>$ radiotherapy $>$ surgery $>$ TACE $>$ intervention (Table VI). No difference was noted in mortality between patients reported from case reports and those from non-case reports (Table VIII).

The pathology of HCC was available for 18 patients: 10 (55.6\%) were moderately differentiated [2, 11, 13, $25,35,42,52], 3(16.7 \%)$ were moderately to poorly differentiated $[7,18,33]$, and $5(27.8 \%)$ were poorly differentiated $[4,11,12,29,30]$.

\section{Discussion}

The etiology of HCC in the present study is comparable to that reported by Wakayama et al. [50], with hepatitis B virus infection being the most common etiology, followed by hepatitis $C$ virus infection. Advanced HCCs are aggressive and refractory, often with multiple focuses, portal and hepatic vein invasions, and extrahepatic metastases to the lungs, adrenal gland and mediastinal lymph node [50]. RA thrombus is an infrequent sequel of advanced HCCs, but prognosis is poor with limited treatment options [41]. The incidence of tumor thrombus may be higher in those patients with a serum a-fetoprotein level $>1,000 \mu \mathrm{g} / \mathrm{L}$ and a tumor size $>5 \mathrm{~cm}[10]$.

Lou et al. [23] applied hypofractionated radiotherapy as a salvage treatment for 1,897 patients with recurrent HCC, 104 patients (5.5\%) were with IVC/RA tumor thrombus. The 1-, 2- and 3-year survival rates of patients with IVC/RA tumor thrombus were $22.2 \%, 11.1 \%$, and $5.6 \%$, respectively, with a mean survival time of $11.6 \pm 2.5$ months [23].

TACE has become a acceptable and safe treatment for unresectable HCCs [54, 55], but extrahepatic collateral artery supply to the tumor thrombus may require sequential repeated TACE, and marked arteriovenous shunts associated with tumor thrombus may limit the therapeutic effect of TACE [56]. TACE with and without combined radiotherapy, and chemotherapy with thalidomide have been reported, but with no reliable evidence of benefits from these treatments [3]. Patients with IVC/RA tumor thrombus treated with TACE had a mean survival time of 4.2 (range, 1.5-76.7) months as reported by Chern et al. [55]. Wang et al. [3] reported the median survival time of such patients was 4.6 months. Duan et al. [11] retrospectively observed 11 cases of HCC with IVC/RA tumor thrombus treated with combined TACE and external beam radiation. They pointed out that all patients died of disease progression, and the median survival time was 21 months. The clinical effects of TACE in the treatment of HCC with IVC/RA tumor thrombus were heterogeneous and warrant further observations [3]. Nevertheless, TACE helps tumor thrombectomy by stabilizing the tumor thrombi, reducing the size, easy removal and preventing fragmentation [42]. 
Liver resection with thrombectomy has been advocated for HCC patients with IVC/RA tumor thrombus, but its curative effect remains debating. Patients may still show a poor prognosis even with surgical treatment [3]. The surgical indications of HCC patients for major hepatectomy were noncirrhotic or cirrhotic patients at Pugh-Child Class A with no portal hypertension and the indocyanine green clearance value is $\leq 12 \%$ at 15 minutes [57]. However, higher values of indocyanine green clearance are not an absolute surgical contraindication as for the possible clearance impairment by tumor-related vascular obstruction [57]. Pesi et al. [35] summarized that RA tumor thrombus removal could be performed in three ways: 1) with the use of THVE of the liver without CPB, which is indicated for tumor thrombi with an initial contiguity to the RA; 2) normothermic CPB with THVE; and 3) CPB with hypothermic circulatory arrest, but its use is limited due to potentially intraoperative bleeding, possible brain damage and postoperative liver dysfunction. Wang et al. [3] reported that they performed cavoatrial thrombectomy for HCC patients with RA thrombus by modifying procedures as minimally invasive as possible depending on the extension of the tumor thrombus. When the tumor thrombus just slightly entered the RA, median sternotomy or thoracotomy and CPB were not used, but THVE was utilized instead. As a consequence, a significant survival benefit of surgical treatment for HCC patients with IVC/RA tumor thrombus was obtained.

Based on Response Evaluation Criteria in Solid Tumor (RECIST), sorafenib showed a dismal response rate of $2 \%$, but a remarkable improvement of overall survival [58]. A modified RECIST (mRECIST) was termed by modifying the target lesion from the entire lesion to only the contrast-enhanced hepatic lesion at the arterial phase of a dynamic imaging technique [59]. Edeline et al. [58] suggested, after retrospectively studied 53 patients with advanced HCC, that mRECIST should be used for the standard assessment of treatment efficacy due to its wider applicability to patients and the usefulness in guiding the continuation of sorafenib.

HCC with macrovascular invasion is an extensively debated topic. Guidelines often struggle to fit these cases in, leaving them in a "grey area". There is increasing evidence suggesting that alternative strategies to sorafenib might improve patients' survival advanced HCC with macrovascular invasion but lack of sufficient evidence [60]. A recent meta-analysis by Chen et al. [61] revealed that the overall survival is higher in hepatectomy than in the TACE group, and that hepatectomy was superior over TACE in 1-year and 3-year, but not 5-year.

Sorafenib is just an effective and safe drug for improving the survival of patients with advanced HCC. Recently, regorafenib was reported to improve survival in a phase 3 clinical trial; however, it is unable to meet the critical need of treatments of progressed patients or those intolerable to sorafenib [62]. Limited armamentarium with the systemic treatment of HCC prompts physicians to seek more effective treatments to extend patients survival.

The prognosis of patients with HCC and tumor thrombus is poor, and the survival time of untreated patients is limited to only 3 days -2 months, whereas liver resection with cavoatrial thrombectomy 
improves patients' survival to 5-56 months [35]. The present study revealed an enhanced survival rate and an elongated survival time of HCC patients receiving active treatments.

The main finding of this study was an improved survival rate of patients receiving TACE and surgical patients. The survival time of patients with TACE treatment was even longer than that of surgical patients, but lack of statistical significance. Thus, active aggressive treatments are advised for advanced HCC patients.

That patient information from heterogeneous reports, based on some case series and a multitude of single case reports, might bring about possible publication biases at an outcome level, and constituted the major drawback of this study. Patients with smaller HCCs have been probably offered surgery while more extensive HCCs have undergone TACE (if not chemotherapy or best supportive care only). Limitations are expected and do not reduce the value of the work.

\section{Conclusions}

Even though advanced HCC with RA thrombus is an aggressive malignancy, the present study showed that patient prognoses were improved and survival time elongated with the advances of active treatments such as TACE and surgical treatments. More abundant patient information from retrospective studies on large patient populations is warranted for obtaining more precise results in future studies.

\section{Abbreviations}

CPB: cardiopulmonary bypass;

HCC: hepatocellular carcinoma;

IVC: inferior vena cava

RA: right atrium;

TACE: transarterial chemoembolization;

THVE: total hepatic vascular exclusion.

\section{Declarations}

Ethics approval and consent to participate: N/A

Consent for publication: The Institutional Ethical Committee agrees to publish this article.

Availability of data and material: N/A

Competing interests: No. 
Funding: No.

Author's contributions: YSM: Substantial contributions to the conception or design of the work; or the acquisition, analysis, or interpretation of data for the work; AND Drafting the work or revising it critically for important intellectual content; AND Final approval of the version to be published; AND Agreement to be accountable for all aspects of the work in ensuring that questions related to the accuracy or integrity of any part of the work are appropriately investigated and resolved. GYX: Final approval of the version to be published; AND Agreement to be accountable for all aspects of the work in ensuring that questions related to the accuracy or integrity of any part of the work are appropriately investigated and resolved.

Acknowledgments: No.

\section{References}

1. Chang JY, Ka WS, Chao TY, Liu TW, Chuang TR, Chen LT. Hepatocellular carcinoma with intra-atrial tumor thrombi. A report of three cases responsive to thalidomide treatment and literature review. Oncology 2004;67(3-4):320-6.

2. Inoue $Y$, Hayashi M, Katsumata T, Shibayama Y, Tanigawa N. Hepatocellular carcinoma with right atrial tumor thrombus: report of a case. Surg Today 2011;41(8):1122-9.

3. Wang Y, Yuan L, Ge RL, Sun Y, Wei G. Survival benefit of surgical treatment for hepatocellular carcinoma with inferior vena cava/right atrium tumor thrombus: results of a retrospective cohort study. Ann Surg Oncol 2013;20(3):914-22.

4. Uemura M, Sasaki Y, Yamada T, Eguchi H, Ohigashi H, Doki Y, Murata K, Miyashiro I, Ishikawa O, Takami H, Kobayashi T, Imaoka S. Surgery for hepatocellular carcinoma with tumor thrombus extending into the right atrium: report of a successful resection without the use of cardiopulmonary bypass. Hepatogastroenterology 2004;51(59):1259-62.

5. Abdelnabi M, Almaghraby A, Saleh Y, Abd Elsamad S. Hepatocellular carcinoma with a direct right atrial extension in an HCV patient previously treated with direct-acting antiviral therapy: a case report. Egypt Heart J 2019;71(1):5.

6. Alraies MC, Khan UA, Alraiyes AH, Auron M. Right atrium tumor thrombus. 2013;106(7):679-80.

7. Ariizumi SI, Kikuchi C, Tokitou F, Yamashita S, Kotera Y, Omori A, Kato T, Nemoto S, Niinami H, Yamamoto M. Cavo-atrial thrombectomy prior to hepatectomy for hepatocellular carcinoma with tumorthrombus in the right atrium: a case report. Surg Case Rep 2019;5(1):57.

8. Bălăceanu LA, Diaconu CC, Aron G. Budd-Chiari syndrome as an initial presentation of hepatocellular carcinoma: a case report. Med Ultrason 2014;16(2):172-4.

9. Chandra P, Shah S, Purandare N, Agrawal A, Rangarajan V. Hepatocellular carcinoma with intraatrial tumor extension identified on $99 \mathrm{mTc}$-labeled macroaggregated albumin single photon emission computed tomography/computed tomography. Indian J Nucl Med 2016;31(4):311-312. 
10. Chen $M$, Huang $X$, Yang Q. Hepatocellular carcinoma with inferior vena cava and right atrial tumor thrombus: A case report. Echocardiography 2019;36(11):2110-2113.

11. Duan F, Yu W, Wang Y, Liu FY, Song P, Wang ZJ, Yan JY, Yuan K, Wang MQ. Trans-arterial chemoembolization and external beam radiation therapy for treatment of hepatocellular carcinoma with a tumor thrombus in the inferior vena cava and right atrium. Cancer Imaging 2015;15:7.

12. Florman S, Weaver M, Primeaux P, Killackey M, Sierra R, Gomez S, Haque S, Regenstein F, Balart L. Aggressive resection of hepatocellular carcinoma with right atrial involvement. Am Surg 2009;75(11):1104-8.

13. Georgen M, Regimbeau JM, Kianmanesh R, Marty J, Farges O, Belghiti J. Removal of hepatocellular carcinoma extending in the right atrium without extracorporal bypass. J Am Coll Surg 2002;195(6):892-4.

14. Ghimire S, Giri S, Morsy M, Hwang I, Alsafwah SF. A case of right atrial thrombus secondary to hepatocellular carcinoma. J Community Hosp Intern Med Perspect 2016;6(3):31443.

15. Giuliani ME, Knox J, Dawson LA. Malignant intracardiac thrombus from hepatocellular carcinoma treated with external beam radiation therapy. J Palliat Med 2010;13(10):1293-5.

16. Hayashida K, Okumura S, Kawase T. Right atrial obstruction due to cardiac extension of hepatocellular carcinoma. Asian Cardiovasc Thorac Ann 2014;22(4):465-8.

17. Kawakami M, Koda M, Mandai M, Hosho K, Murawaki Y, Oda W, Hayashi K. Isolated metastases of hepatocellular carcinoma in the right atrium: Case report and review of the literature. Oncol Lett 2013;5(5):1505-1508.

18. Leo F, Rapisarda F, Stefano PL, Batignani G. Cavo-atrial thrombectomy combined with left hemihepatectomy for vascular invasion fromhepatocellular carcinoma on diseased liver under hypothermic cardio-circulatory arrest. Interact Cardiovasc Thorac Surg 2010;10(3):473-5.

19. Leong K, Kuppasani K, Pyrsopoulos N. Atrial tumor thrombus: A rare complication of hepatocellular carcinoma. JAAPA 2019;32(2):23-26.

20. Li AJ, Yuan H, Yin L, Che Q, Lang XL, Wu MC. Cavoatrial thrombectomy in hepatocellular carcinoma with tumor thrombus in the vena cava and atrium without the use of cardiopulmonary bypass. Ann Vasc Surg 2014;28(6):1565.e5-8.

21. Li SS, Jian LL, Gang PB, Ando KM, Ming LD. Removal of hepatocellular carcinoma extending into the right atrium with extracorporeal circulation. Hepatogastroenterology 2012;59(117):1591-3.

22. Li W, Wang Y, Gao W, Zheng J. HCC with tumor thrombus entering the right atrium and inferior vena cava treated by percutaneous ablation. BMC Surg 2017;17(1):21.

23. Lou J, Li Y, Liang K, Guo Y, Song C, Chen L, Wang L, Wang F, Zhang L, Chen X, Xu X, Pan M. Hypofractionated radiotherapy as a salvage treatment for recurrent hepatocellular carcinoma with inferior vena cava/right atrium tumor thrombus: a multi-center analysis. BMC Cancer 2019;19(1):668.

24. Lourenço LC, Horta DV, Alberto SF, Reis J. Hepatocellular carcinoma presenting with Budd-Chiari syndrome, right atrial thrombus and pulmonary emboli. Rev Esp Enferm Dig 2017;109(4):296-297. 
25. Lubezky N, Nachmany I, Goykhman Y, Ben-Gal Y, Menachem Y, Geva R, Klausner JM, Nakache R. Surgical treatment of hepatocellular carcinoma with a tumor thrombus extending into the right atrium. Isr Med Assoc J 2018;20(9):590-591.

26. Luo X, Zhang B, Dong S, Zhang B, Chen X. hepatocellular carcinoma with tumor thrombus occupying the right atrium and portal vein: a case report and literature review. Medicine (Baltimore) 2015;94(34):e1049.

27. Mancusi V, Ponsiglione A, Gambardella M, Imbriaco M. Unique association of cardiac amyloidosis and right atrial tumor thrombus in a patient with hepatocellular carcinoma. Radiol Case Rep 2019;14(9):1140-1143.

28. Mikhno L, Afzal A, Sonawala T, Palta S, Worku B, Gulkarov I. Hepatocellular carcinoma presenting as an incidental right atrial J Card Surg 2016;31(1):60.

29. Miyazawa M, Torii T, Asano H, Yamada M, Toshimitsu Y, Shinozuka N, Koyama I. Does a surgery for hepatocellular carcinoma with tumor thrombus highly occupying in the rightatrium have significance? A case report and review of the literature. Hepatogastroenterology 2005;52(61):212-6.

30. Ohta M, Nakanishi C, Kawagishi N, Hara Y, Maida K, Kashiwadate T, Miyazawa K, Yoshida S, Miyagi S, Hayatsu Y, Kawamoto S, Matsuda Y, Okada Y, Saiki Y, Ohuchi N. Surgical resection of recurrent extrahepatic hepatocellular carcinoma with tumor thrombusextending into the right atrium under cardiopulmonary bypass: a case report and review of the literature. Surg Case Rep 2016;2(1):110.

31. Ohwada S, Takahashi T, Tsutsumi H, Kawate S, Ohki S, Hamada K. Hepatocellular carcinoma with a tumour thrombus extending to the tricuspid valve: report of a successful en bloc resection. Hepatogastroenterology 2008;55(84):903-6.

32. Panduranga P, Al-Mukhaini M, Ratnam L, Al-Harthy S. Mobile right atrial thrombus with pulmonary thromboembolism in a patient with advancedhepatocellular carcinoma and disseminated tumor thrombosis. Heart Views 2011;12(4):173-7.

33. Pandya H, Shah C, Lakhani J, Patel M. Intra-atrial tumour thrombus secondary to hepatocellular carcinoma. Australas Med J 2013;6(6):321-4.

34. Pellicelli AM, Barbaro G, Soccorsi F. Contrast echocardiography of right atrial mass due to hepatocellular carcinoma. Acta Cardiol. 2006 Aug;61(4):471-3.

35. Pesi B, Giudici F, Moraldi L, Montesi G, Romagnoli S, Pinelli F, Stefano P, Batignani G. Hepatocellular carcinoma on cirrhosis complicated with tumoral thrombi extended to the rightatrium: results in three cases treated with major hepatectomy and thrombectomy under hypothermic cardiocirculatory arrest and literature review. World J Surg Oncol 2016;14:83.

36. Rallidis LS, Papadopoulos CC, Kelekis NL, Kremastinos DT. The role of myocardial contrast echocardiography to assess the origin of a mass in right cardiac cavities. Echocardiography 2009;26(1):88-92.

37. Rose D, Chirichilli I, D'Ascoli R, D'Alessandro G, Madeo A, Toscano F, Cavarretta E, Truscelli G, Peruzzi M. Giant right atrial thrombus in hepatocellular carcinoma: real-time characterization by cardiac 
magnetic resonance and real time three-dimensional echocardiography. Eur Rev Med Pharmacol Sci 2012;16 Suppl 4:81-3.

38. Sabzi F, Heidari A, Faraji R. Isolated Right Atrial Mass in a Candidate of Coronary Bypass Grafting. Acta Med Iran 2017;55(11):722-725.

39. Saynak M, Ozen A, Kocak Z, Cosar-Alas R, Uzal C. Sudden death: a case report of hepatocellular carcinoma with tumor thrombus extending into theright atrium. J BUON 2007;12(4):556.

40. Sempokuya T, Bolger DT Jr. Right atrium invasion of tumor thrombus from hepatocellular carcinoma incidentally found on transthoracic echocardiogram. Hawaii J Med Public Health 2018;77(6):131-134.

41. Sengodan P, Grewal H, Gandhi S. Invasive hepatocellular carcinoma with recurrent pulmonary embolism: use of AngioVac cannula thrombectomy device for mechanical aspiration. J Invasive Cardiol 2014;26(7):E100-3.

42. Shivathirthan N, Shimoda M, Kosuge T, Kato M, Kijima H, Sawada T, Kubota K. Recurrent hepatocellular carcinoma with tumor thrombus in right atrium - report of a successful liver resection with tumor thrombectomy using total hepatic vascular exclusion without concomitant cardiopulmonary bypass. Hepatogastroenterology 2012;59(115):872-4.

43. Shudo Y, Matsumiya G, Sakaguchi T, Fujita T, Yamauchi T, Sawa Y. Resection of advanced stage malignant retroperitoneal neoplasms with tumor thrombus extending into the right atrium: report of four cases. Surg Today 2011;41(2):262-5.

44. Siddiqui MU, Khan M, Anderson T. right atrial mass in a patient with hiv and hepatitis B: a case report. Cardiol Res 2013;4(4-5):165-167.

45. Subramanian R, Singh SA, Gupta S, Majhi SK, Malhotra R. Perioperative anesthetic management of a combined right atrial thrombectomy with living donor liver transplantation. J Anaesthesiol Clin Pharmacol 2019;35(3):396-399.

46. Sun JH, Zhang YL, Nie CH, Chen LM, He JD, Wang WL, Zheng SS. Long-term survival after chemoembolization of metastatic right atrial tumor thrombus as a presenting feature of hepatocellular carcinoma: A case study. Oncol Lett 2012;3(5):975-977.

47. Sundriyal D, Bhargava S, Sharma N, Gera A. Cannon Ball Metastases and Atrial Thrombus. Indian J Surg Oncol 2015;6(3):311-2.

48. Sung AD, Cheng S, Moslehi J, Scully EP, Prior JM, Loscalzo J. Hepatocellular carcinoma with intracavitary cardiac involvement: a case report and review of the literature. Am J Cardiol 2008;102(5):643-5.

49. Vicente E, Quijano Y, lelpo B, De Luca GM, Prestera A, Duran H, Diaz E, Fabra I, Olivares S, Caruso R. Cavoatrial thrombectomy without the use of cardiopulmonary bypass for abdominal tumors. Our experience and state of the art. Ann Vasc Surg 2015;29(5):1020.e1-5.

50. Wakayama K, Kamiyama T, Yokoo H, Kakisaka T, Kamachi H, Tsuruga Y, Nakanishi K, Shimamura T, Todo S, Taketomi A. Surgical management of hepatocellular carcinoma with tumor thrombi in the inferior vena cava orright atrium. World J Surg Oncol 2013;11:259. 
51. Wu CC, Hseih S, Ho WM, Tang JS, Liu TJ, P'eng FK. Surgical treatment for recurrent hepatocellular carcinoma with tumor thrombi in right atrium: using cardiopulmonary bypass and deep hypothermic circulatory arrest. J Surg Oncol 2000;74(3):227-31.

52. Yogita S, Tashiro S, Harada M, Kitagawa T, Kato I. Hepatocellular carcinoma with extension into the right atrium: report of a successful liver resection by hepatic vascular exclusion using cardiopulmonary bypass. J Med Invest 2000;47(3-4):155-60.

53. Zhu L, Yang R, Zhu X. Transcatheter arterial chemoembolization experience for advanced hepatocellular carcinoma withright atrial tumor thrombus. J Cancer Res Ther 2019;15(2):305-311.

54. Bruix J, Sherman M; American Association for the Study of Liver Diseases. Management of hepatocellular carcinoma: an update. Hepatology 2011;53(3):1020-2.

55. Chern MC, Chuang VP, Cheng T, Lin ZH, Lin YM. Transcatheter arterial chemoembolization for advanced hepatocellular carcinoma with inferior vena cava and right atrial tumors. Cardiovasc Intervent Radiol 2008;31(4):735-44.

56. Izaki K, Sugimoto K, Sugimura K, Hirota S. Transcatheter arterial embolization for advanced tumor thrombus with marked arterioportal or arteriovenous shunt complicating hepatocellular carcinoma. Radiat Med 2004;22(3):155-62.

57. Le Treut YP, Grégoire E, Fara R, Giuly JA, Chopinet S, Delpero JR, Hardwigsen J. The technique and outcomes of central hepatectomy by the Glissonian suprahilar approach. Eur J Surg Oncol 2019;45(12):2369-2374.

58. Edeline J, Boucher E, Rolland Y, Vauléon E, Pracht M, Perrin C, Le Roux C, Raoul JL. Comparison of tumor response by Response Evaluation Criteria in Solid Tumors (RECIST) and modified RECIST in patients treated with sorafenib for hepatocellular carcinoma. Cancer 2012;118(1):147-56.

59. Eisenhauer EA, Therasse P, Bogaerts J, Schwartz LH, Sargent D, Ford R, Dancey J, Arbuck S, Gwyther S, Mooney M, Rubinstein L, Shankar L, Dodd L, Kaplan R, Lacombe D, Verweij J. New response evaluation criteria in solid tumours: revised RECIST guideline (version 1.1). Eur $\mathrm{J}$ Cancer 2009;45(2):228-47.

60. Costentin CE, Ferrone CR, Arellano RS, Ganguli S, Hong TS, Zhu AX. Hepatocellular carcinoma with macrovascular invasion: defining the optimal treatment strategy. Liver Cancer 2017;6(4):360-74.

61. Chen J, Huang J, Chen M, YangK, Chen J, Wang J, et al. Transcatheter arterial chemoembolization (TACE) versus hepatectomy in hepatocellular carcinoma with macrovascular invasion: a metaanalysis of 1683 patients. J Cancer 2017;8(15):2984-2991.

62. Ribeiro de Souza A, Reig M, Bruix J. Systemic treatment for advanced hepatocellular carcinoma: the search of new agents to join sorafenib in the effective therapeutic armamentarium. Expert Opin Pharmacother 2016;17(14):1923-36.

\section{Tables}

Table I. Medical history of liver disease 


\begin{tabular}{|c|c|}
\hline Liver disease & $\mathrm{n}(\%)$ \\
\hline Hepatitis B & $108(57.8)$ \\
\hline Hepatitis B infection $[3,20,22,26]$ & $58(53.7)$ \\
\hline Hepatitis $B$ antigen positive $[10,13,21,23,32-34,46,47,50]$ & $33(30.6)$ \\
\hline Chronic hepatitis B $[8,11,12,15,17,25,44]$ & $17(15.7)$ \\
\hline Hepatitis C & $17(9.1)$ \\
\hline Chronic hepatatis C $[1,18,19,29,30,38,42,45,52]$ & $10(58.8)$ \\
\hline Hepatitis $C$ virus antibody positive $[5,27,31,50]$ & $5(29.4)$ \\
\hline Hepatitis C virus RNA very high [24] & $1(5.9)$ \\
\hline Hepatitis C virus-related end-stage liver disease [1] & $1(5.9)$ \\
\hline Chronic hepatitis, unspecified [39] & $1(0.5)$ \\
\hline Hepatitis, autoimmune [40] & $1(0.5)$ \\
\hline Cirrhosis $[1,19,34,45,51]$ & $7(3.7)$ \\
\hline Hepatocellular carcinoma $[1,5,15,19,20,23,30,34,36-38,40,45,48,51]$ & $32(17.1)$ \\
\hline Human immunodeficiency virus infection [44] & $1(0.5)$ \\
\hline
\end{tabular}

Table II. 96 clinical symptoms in 36 patients 


\begin{tabular}{|c|c|}
\hline Symptom & $\mathrm{n}(\%)$ \\
\hline Edema, lower extremity $[5,7-10,14,16,34,39,42,45,46,51]$ & $\begin{array}{l}13 \\
(13.5)\end{array}$ \\
\hline Ascites $[1,5,8,19,21,24,34,39,42,51]$ & $\begin{array}{l}10 \\
(10.4)\end{array}$ \\
\hline $\begin{array}{l}\text { Abdominal distension/increase of abdominal volume }[1,16,19,24,26,32,34 \text {, } \\
45,51]\end{array}$ & $9(9.4)$ \\
\hline Abdominal pain $[1,8,14,21,24,32,33,38,39]$ & $9(9.4)$ \\
\hline Dyspnea $[1,5,16,19,28,32,39,51]$ & $9(9.4)$ \\
\hline Shortness of breath $[6,8,15,24,41,44]$ & $6(6.3)$ \\
\hline Poor appetite $[6,9,14,19,32]$ & $5(5.2)$ \\
\hline Weight loss $[8,12,13,32]$ & $4(4.2)$ \\
\hline Asymptomatic $[2,20,22,25]$ & $4(4.2)$ \\
\hline Altered mental status $[6,16]$ & $2(2.1)$ \\
\hline Asthenia/weakness $[13,19]$ & $2(2.1)$ \\
\hline Chest distress $[19,46]$ & $2(2.1)$ \\
\hline Chest pain $[41,44]$ & $2(2.1)$ \\
\hline Epigastralgia $[6,7]$ & $2(2.1)$ \\
\hline Others & $\begin{array}{l}17 \\
(17.7)\end{array}$ \\
\hline
\end{tabular}

Table III. Laboratory investigations 


\begin{tabular}{|c|c|c|c|c|c|}
\hline Parameter & Mean \pm SD & Range & Median & Normal/abnormal & $\mathrm{n}$ \\
\hline $\begin{array}{l}\text { Total bilirubin }(\mathrm{mg} / \mathrm{dL}) \\
{[1-4,8-10,14,15,17-} \\
21,25,32,33,38,45, \\
46,51,52]\end{array}$ & $1.5 \pm 0.8$ & $0.4-2.9$ & 1.1 & $10 / 16$ & 26 \\
\hline $\begin{array}{l}\text { Album }(g / d L) \quad[1-4,7,8, \\
18-21,25,30,32,35,38, \\
44-46,51,52]\end{array}$ & $3.5 \pm 0.7$ & $1.9-5.1$ & 3.6 & $10 / 16$ & 26 \\
\hline $\begin{array}{l}\alpha \text {-fetoprotein }(\mu \mathrm{g} / \mathrm{L}) \\
2,4,6-12,14-17,19-22, \\
24-27,29-33,35,38-41, \\
46,47,51,52]\end{array}$ & $25,411.9 \pm 104988.5$ & $\begin{array}{l}2.01- \\
687,460\end{array}$ & 585 & $18 / 34$ & 51 \\
\hline $\begin{array}{l}\text { Alkaline } \text { phosphatase } \\
(\mathrm{U} / \mathrm{L})[1,6,14,17-19, \\
32,33]\end{array}$ & $219.6 \pm 170.9$ & $40-491$ & 141.5 & $3 / 5$ & 8 \\
\hline $\begin{array}{l}\text { Aspartate } \\
\text { aminotransferase }(\mathrm{U} / \mathrm{L}) \\
\begin{array}{l}1,2,6,7,10,14,15, \\
17-21,25,27,32,33,35, \\
52]\end{array}\end{array}$ & $114.8 \pm 103.3$ & $19-441$ & 61 & $3 / 19$ & 22 \\
\hline $\begin{array}{l}\text { Indocyanin } \text { green } \\
\text { retention test at } 15 \mathrm{~min} \\
(\%)[2,4,18,35,51,52]\end{array}$ & $23.3 \pm 16.4$ & 8.7-61.4 & 20.7 & $1 / 7$ & 8 \\
\hline
\end{tabular}

Table IV. Tumor thrombus-invaded vasculatures 


\begin{tabular}{|l|c|}
\hline Tumor thrombus-invaded vasculature & $\mathrm{n}(\%)$ \\
\hline Inferior vena cava $[1,2,4,5,6,8-11,13-41,44-52]$ & $80(42.8)$ \\
\hline Portal vein $[6-8,12,17,19,26,33-35,37,39,40,44]$ & $17(9.1)$ \\
\hline Left $[33,35]$ & $2(11.8)$ \\
\hline Main $[6,12]$ & $2(11.8)$ \\
\hline Unspecified & $13(76.5)$ \\
\hline Hepatic vein & $46(25.6)$ \\
\hline Left [2, 26, 50, 53] & $5(10.9)$ \\
\hline Left \& middle $[1,18,35,45,50]$ & $6(13.0)$ \\
\hline Middle [1, 25, 29,50,52,53] & $10(21.7)$ \\
\hline Right [4, 10, 20, 28, 40,49,50,53] & $21(45.7)$ \\
\hline Accessory [22] & $1(2.2)$ \\
\hline Unspecified [7, 9, 44] & $3(6.5)$ \\
\hline Renal vein & $2(1.1)$ \\
\hline Left [16] & $1(50)$ \\
\hline Right [48] & $1(50)$ \\
\hline Segmental/subsegmental pulmonary artery [17, 41] & $2(1.1)$ \\
\hline
\end{tabular}

Table V. Patients' outcomes 


\begin{tabular}{|c|c|c|c|}
\hline Treatment & Alive & Dead & Unknown \\
\hline TACE $(n=38)$ & $8(21.1)$ & $9(23.7)$ & $21(55.3)$ \\
\hline Sole TACE $(n=21)$ & $1(4.8)$ & $2(9.5)$ & $18(85.7)$ \\
\hline TACE + chemotherapy $(n=3)$ & $2(66.7)$ & $1(33.3)$ & \\
\hline TACE +radiotherapy $(n=11)$ & $2(18.2)$ & $6(54.5)$ & $3(27.3)$ \\
\hline TACE+radiotherapy+surgery $(n=1)$ & $1(100)$ & & \\
\hline TACE + surgery $(n=2)$ & $2(100)$ & & \\
\hline Surgery $(n=27)$ & $9(33.3)$ & $14(51.9)$ & $4(14.8)$ \\
\hline Sole surgery $(n=21)$ & 7 (33.3) & $11(52.4)$ & $3(14.3)$ \\
\hline Surgery+TACE $(n=3)$ & & $3(100)$ & \\
\hline Surgery+chemotherapy $(n=3)$ & $2(66.7)$ & & $1(33.3)$ \\
\hline Radiotherapy $(\mathrm{n}=19)$ & $2(10.5)$ & $17(89.5)$ & \\
\hline Chemotherapy $(\mathrm{n}=4)$ & & & $4(100)$ \\
\hline Intervention $(\mathrm{n}=2)$ & $1(50)$ & $1(50)$ & \\
\hline Interventional+chemotherapy $(n=1)$ & & $1(100)$ & \\
\hline Interventional+ TACE $(n=1)$ & $1(100)$ & & \\
\hline Supportive $(n=7)$ & & $5(71.4)$ & $2(28.6)$ \\
\hline Untreated $(\mathrm{n}=4)$ & & $1(25)$ & $3(75)$ \\
\hline
\end{tabular}

TACE: transarterial chemoembolization.

Table VI. Morbidity, mortality and follow-up 


\begin{tabular}{|c|c|c|c|}
\hline Treatment & $\begin{array}{l}\text { Morbidity, } \mathrm{n} \\
(\%)\end{array}$ & $\begin{array}{l}\text { Mortality, } \mathrm{n} \\
(\%)\end{array}$ & $\begin{array}{l}\text { Follow-up, mean } \pm \text { SD (range; median) } \\
\text { (month) }\end{array}$ \\
\hline TACE $(n=38)$ & $2(5.3)$ & $9(52.9,9 / 17)$ & $13.2 \pm 13.3(1.3-56 ; 6.5)$ \\
\hline Surgery $(n=27)$ & $14(51.9)$ & $\begin{array}{l}14 \quad(60.9, \\
14 / 23)\end{array}$ & $18.7 \pm 19.7(0.5-97 ; 12)$ \\
\hline $\begin{array}{l}\text { Radiotherapy } \\
(\mathrm{n}=19)\end{array}$ & $1(5.3)$ & $\begin{array}{l}17 \quad(89.5, \\
17 / 19)\end{array}$ & $21.5 \pm 20.5(7-36 ; 39.5)$ \\
\hline $\begin{array}{l}\text { Chemotherapy } \\
(\mathrm{n}=4)\end{array}$ & -- & -- & -- \\
\hline $\begin{array}{l}\text { Intervention } \\
(\mathrm{n}=2)\end{array}$ & $1(50)$ & $1(50,1 / 2)$ & $9.0 \pm 9.9(2-16 ; 9)$ \\
\hline Supportive $(n=7)$ & -- & $5(100,5 / 5)$ & $2.3 \pm 2.2$ \\
\hline Untreated & -- & -- & $3.2 \pm 2.6(1.3-5 ; 3.2)$ \\
\hline
\end{tabular}

TACE: transarterial chemoembolization.

Table VII. Morbidities

\begin{tabular}{|c|l|l|l|l|}
\hline Morbidity & $\begin{array}{l}\text { Surgery } \\
(\mathrm{n}=14)\end{array}$ & $\begin{array}{l}\text { TACE } \\
(\mathrm{n}=2)\end{array}$ & $\begin{array}{l}\text { Radiotherapy } \\
(\mathrm{n}=1)\end{array}$ & $\begin{array}{l}\text { Intervention } \\
(\mathrm{n}=1)\end{array}$ \\
\hline Hepatic recurrence $(\mathrm{n}=15)$ & $12(85.7)$ & $1(50)$ & $1(100)$ & $1(100)$ \\
\hline Intrahepatic $(n=3)$ & $2(16.7)$ & & $1(100)$ & $1(100)$ \\
\hline Extrahepatic $(n=6)$ & $5(41.7)$ & & & \\
\hline $\begin{array}{c}\text { Intra- \& extrahepatic } \\
(n=3)\end{array}$ & $3(25)$ & & 1 & \\
\hline $\begin{array}{c}\text { Diffuse (n=1) } \\
\text { Unspecified }\end{array}$ & $2(16.7)$ & $(100)$ & & \\
\hline $\begin{array}{l}\text { Lung infection (n=1) } \\
(\mathrm{n}=2)\end{array}$ & $2(14.3)$ & & & \\
\hline Organ failure/septic shock & & & & \\
\hline
\end{tabular}


TACE: transarterial chemoembolization.

Table VIII. A comparison of mortality between patients reported in case reports and those in non-case reports, n (\%)

\begin{tabular}{|l|l|l|l|l|}
\hline Treatment & Case report & Non-case report & $\chi^{2}$ & $p$ value \\
\hline TACE & $2(40,2 / 5)$ & $8(24.2,8 / 33)$ & 0.0 & 0.833 \\
\hline Surgery & $8(50,8 / 16)$ & $6(66.7,6 / 9)$ & 0.0 & 0.833 \\
\hline Radiotherapy & $1(100,1 / 1)$ & $2(0,0 / 2)$ & 0.0 & 0.833 \\
\hline Chemotherapy & $?(? / 4)$ & & & \\
\hline Intervention & $1(50,1 / 2)$ & & & \\
\hline Supportive & $5(71.4,5 / 7)$ & & & \\
\hline Untreated & $1(33.3,1 / 3)$ & $?(? / 1)$ & & \\
\hline
\end{tabular}

TACE: transarterial chemoembolization.

\section{Figures}




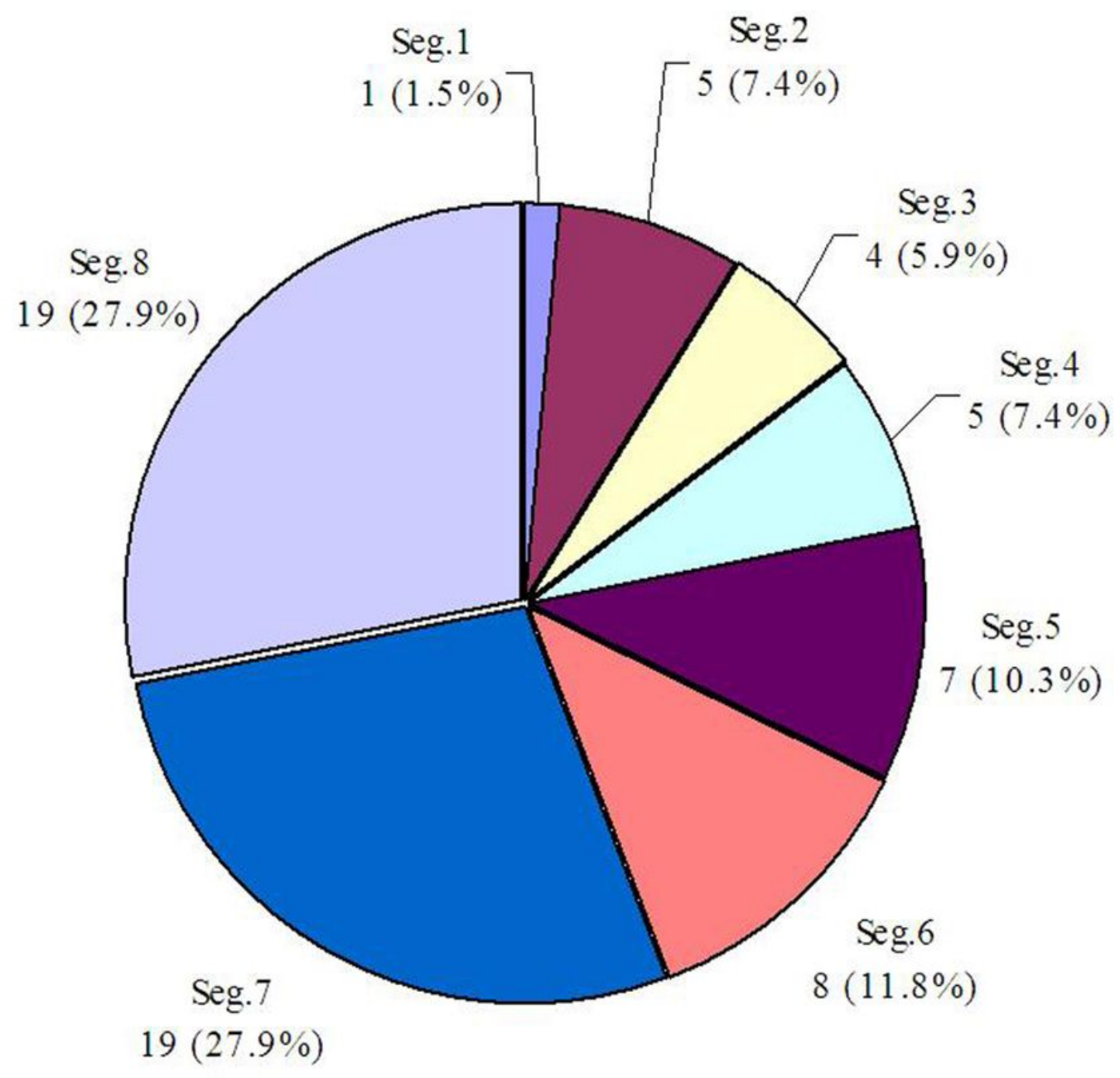

Figure 1

The distribution of segmental invasion of the liver by hepatocellular carcinoma. Seg.: segment.

\section{Supplementary Files}

This is a list of supplementary files associated with this preprint. Click to download.

- PRISMA2009checklist.doc 